\title{
Article \\ Modulating the ERK1/2-MMP1 Axis through Corosolic Acid Inhibits Metastasis of Human Oral Squamous Cell Carcinoma Cells
}

\author{
Jen-Liang Chen ${ }^{1,+}$, Chung-Yu Lai ${ }^{2, \dagger}$, Tsung-Ho Ying ${ }^{3,4}$, Chiao-Wen Lin ${ }^{5}$, Pei-Han Wang ${ }^{6}$, Fang-Jung Yu ${ }^{7,8}$, \\ Chung-Jung Liu $7,9, * \mathbb{D}$ and Yi-Hsien Hsieh 6,10,*D
}

Citation: Chen, J.-L.; Lai, C.-Y.; Ying, T.-H.; Lin, C.-W.; Wang, P.-H.; Yu, F.-J.; Liu, C.-J.; Hsieh, Y.-H. Modulating the ERK1/2-MMP1 Axis through Corosolic Acid Inhibits Metastasis of Human Oral Squamous Cell Carcinoma Cells. Int. J. Mol. Sci. 2021, 22, 8641. https://doi.org/10.3390/ ijms22168641

Academic Editors: Michele Navarra, Thomas Efferth, Santa Cirmi and Alessandro Maugeri

Received: 2 July 2021

Accepted: 7 August 2021

Published: 11 August 2021

Publisher's Note: MDPI stays neutral with regard to jurisdictional claims in published maps and institutional affiliations.

Copyright: (c) 2021 by the authors. Licensee MDPI, Basel, Switzerland. This article is an open access article distributed under the terms and conditions of the Creative Commons Attribution (CC BY) license (https:// creativecommons.org/licenses/by/ $4.0 /)$.
1 Department of Hematology \& Oncology, Chung-Kang Branch, Cheng Ching Hospital, Taichung 40764, Taiwan; jenliangchen@yahoo.com.tw

2 Director of Surgery Department, Chung-Kang Branch, Cheng Ching General Hospital, Taichung 40764, Taiwan; 6976@ccgh.com.tw

3 Department of Obstetrics and Gynecology, Chung Shan Medical University Hospital, Taichung 40201, Taiwan; ying.steve@gmail.com

4 Department of Obstetrics and Gynecology, School of Medicine, College of Medicine, Chung Shan Medical University, Taichung 40201, Taiwan

5 Institute of Oral Sciences, Chung Shan Medical University, Taichung 40201, Taiwan; cwlin@csmu.edu.tw

6 Institute of Medicine, Chung Shan Medical University, Taichung 40201, Taiwan; u9807410@gmail.com

7 Division of Gastroenterology, Department of Internal Medicine, Kaohsiung Medical University Hospital, Kaohsiung Medical University, Kaohsiung 80708, Taiwan; yufj@kmu.edu.tw

8 Department of Medicine, Faculty of Medicine, College of Medicine, Kaohsiung Medical University, Kaohsiung 80708, Taiwan

9 Regenerative Medicine and Cell Therapy Research Center, Kaohsiung Medical University, Kaohsiung 80708, Taiwan

10 Department of Medical Research, Chung Shan Medical University Hospital, Taichung 40201, Taiwan

* Correspondence: 1020590@ms.kmuh.org.tw (C.-J.L.); hyhsien@csmu.edu.tw (Y.-H.H.)

+ These authors contributed equally to this work.

Abstract: Corosolic acid (CA; $2 \alpha$-hydroxyursolic acid) is a natural pentacyclic triterpenoid with antioxidant, antitumour and antimetastatic activities against various tumour cells during tumourigenesis. However, CA's antitumour effect and functional roles on human oral squamous cell carcinoma (OSCC) cells are utterly unknown. In this study, our results demonstrated that CA significantly exerted an inhibitory effect on matrix metalloproteinase (MMP) 1 expression, cell migration and invasion without influencing cell growth or the cell cycle of human OSCC cells. The critical role of MMP1 was confirmed using the GEPIA database and showed that patients have a high expression of MMP1 and have a shorter overall survival rate, confirmed on the Kaplan-Meier curve assay. In the synergistic inhibitory analysis, CA and siMMP1 co-treatment showed a synergically inhibitory influence on MMP1 expression and invasion of human OSCC cells. The ERK1/2 pathway plays an essential role in mediating tumour progression. We found that CA significantly inhibits the phosphorylation of ERK1/2 dose-dependently. The ERK1/2 pathway played an essential role in the CA-mediated downregulation of MMP1 expression and in invasive motility in human OSCC cells. These findings first demonstrated the inhibitory effects of CA on OSCC cells' progression through inhibition of the ERK1/2-MMP1 axis. Therefore, CA might represent a novel strategy for treating OSCC.

Keywords: corosolic acid; human oral squamous cell carcinoma cells; metastasis; ERK1/2; MMP1

\section{Introduction}

Oral squamous cell carcinoma (OSCC) is the most common malignant subgroup of head and neck cancers. OSCC is life threatening, mainly occurs between 40 and 70 years of age and is the leading cause of death, particularly in men. OSCC, which includes 
cancers of the lips, tongue, cheeks, gingiva, the floor of the mouth, buccal mucosa, palate and pharynx, is associated with risk factors including alcohol consumption, betel quid chewing, radiation and viral infections [1,2]. The invasion and metastasis of OSCC cells are factors in the high mortality rate [3,4]. Thus far, invasion and metastasis are still the target issues for improving the poor clinical outcomes and high mortality rates in patients with cancer. Metastasis accelerates cancer progression through multiple events involving cell migration, cell invasion, angiogenesis and extracellular matrix (ECM) disruption [5,6]. ECM degradation by extracellular proteinases is crucial for tumour cell invasion, metastasis and malignant progression [7]. Thus, the prevention/inhibition of ECM degradation through targeting proteinases, such as matrix metalloproteinases (MMPs), is considered a critical step for cancer therapy $[8,9]$.

MMPs are a family of zinc-dependent endopeptidases and are overexpressed in several malignant tumours. Among MMPs, MMP1 is known as collagenase and degrades collagen type I and III by recognizing the substrate through a hemopexin-like domain [10]. MMP1 is highly expressed in driving tumour progression in aggressive lung cancer [11] and contributes to the migration and invasion of hepatocellular carcinoma cells [12]. MMP1 is also upregulated to promote an invasive brain phenotype in metastatic breast cancer cells [13]. Therefore, targeting MMP1 is considered an essential step for suppressing cancer progression. The effects of corosolic acid (CA) on MMP1 expression and the invasive motility of OSCC cells, the related molecular mechanisms behind CA-antitumour, are investigated in detail in this study.

Potential natural phytochemicals against cancers have been investigated due to the properties of less toxicity and more efficient treatment. CA, a natural pentacyclic triterpenoid, is the principal component of Lagerstroemia speciosa leaves (also called Banaba). Accumulating studies have indicated that CA exerts biological properties including anticancer, antidiabetes, antiobesity, antiinflammation, antihyperlipidaemic and antiviral effects [14]. CA induces ER-stress-dependent apoptosis in human prostate cancer cells [15]. In addition, $\mathrm{CA}$ inhibits cancer progression through inactivating the Yes-associated protein (YAP) in hepatocellular carcinoma [16]. However, CA's antitumour effects and molecular mechanisms in human OSCC cells have not yet been investigated. We determined that corosolic acid (CA) has antitumor effects against human OSCC cells, including growth inhibition, cell cycle arrest, apoptosis induction, migration and invasion suppression. Next, we identified the molecular mechanism behind CA-inhibited OSCC progression. This study demonstrated that $\mathrm{CA}$ inhibits cell migration and invasion by inhibition of the ERK1/2-MMP1 axis in human OSCC cells.

\section{Results}

\subsection{Effect of CA on Cell Viability and Colony Formation of OSCC Cells}

The CA ( $2 \alpha$-hydroxyursolic acid) structure is shown in Figure 1A. The influence of CA on cell viability and colony formation was studied in two cell lines, HSC3 (human tongue squamous carcinoma cell line) and SAS (human tongue squamous carcinoma cell line). Both HSC3 and SAS cell lines were treated with various concentrations $(0,2.5,5,10$, 15 and $20 \mu \mathrm{M})$ of CA for 24 or $48 \mathrm{~h}$, after which cellular viability was analysed using the 3-(4,5-dimethylthiazol-2-yl)-2,5-diphenyl-tetrazolium bromide (MTT) assay. Cell viability was significantly decreased using CA (15 and $20 \mu \mathrm{M})$ in the HSC 3 and SAS cell lines at 24 and $48 \mathrm{~h}$ (Figure 1B) but did not affect cell growth in DMSO (0.04\%)-treated HSC3 and SAS cells (Supplementary Figure S1A). The cell proliferation rate was further measured using a colony formation assay to confirm the inhibitory effect on the growth of HSC3 and SAS cells exposed to $\mathrm{CA}(0,2.5,5,10,15$ and $20 \mu \mathrm{M})$ for $5 \mathrm{~d}$ (Figure 1C). These findings revealed that high concentrations of $\mathrm{CA}(15$ and $20 \mu \mathrm{M})$ exerted a cytotoxic effect on the growth of human OSCC cells. Therefore, we used CA at concentrations $<15 \mu \mathrm{M}$ in the subsequent experiments. 
A

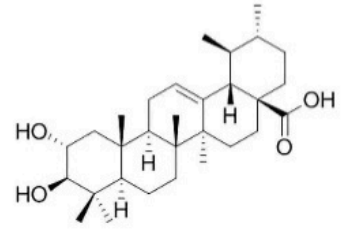

Corosolic acid (CA)
B

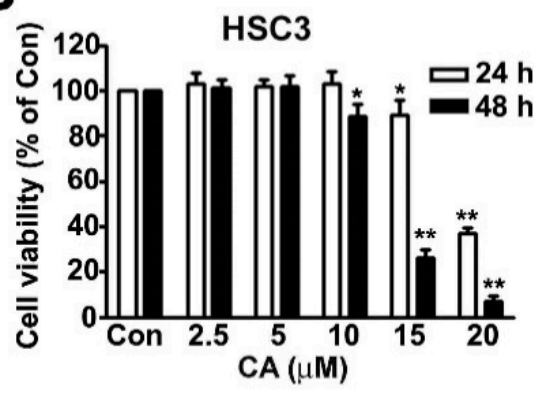

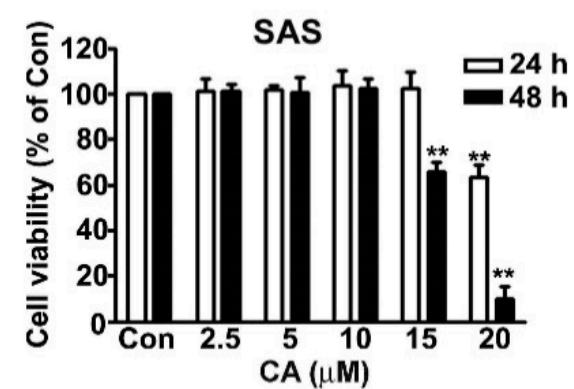

CA $(\mu \mathrm{M})$
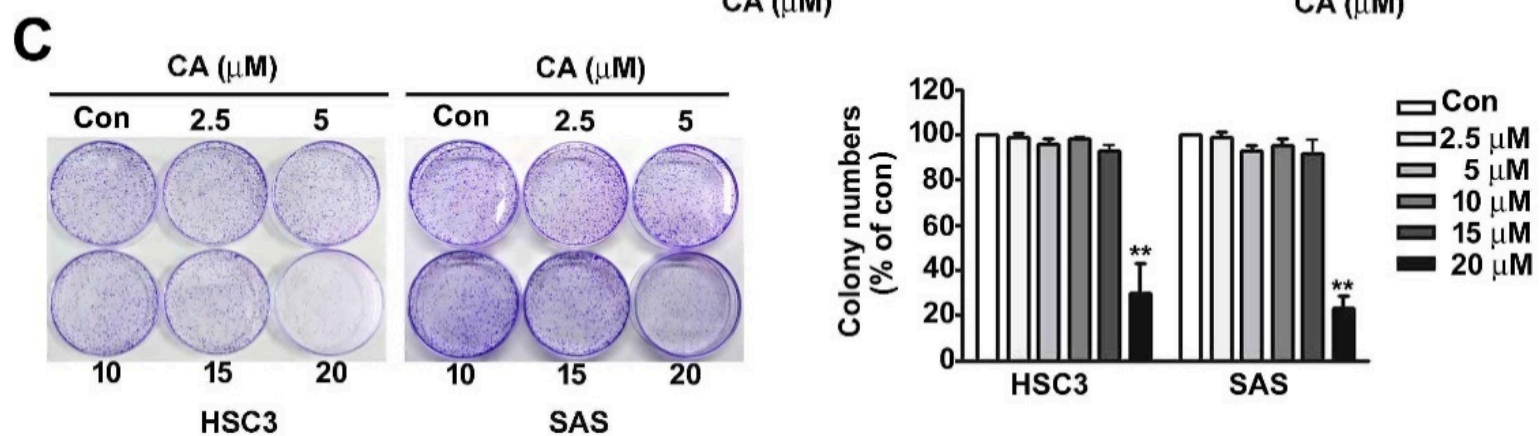

Figure 1. Effect of CA on the viability and cytotoxicity of human HSC3 and SAS OSCC cells. (A) Structure of corosolic acid (CA). (B) Human HSC3 and SAS cells were exposed to various concentrations $(0,2.5,5,10,15$ and $20 \mu \mathrm{M})$ of CA for 24 and $48 \mathrm{~h}$ and then measured to observe cell viability using MTT assay. (C) The cell proliferation rates of human HSC 3 and SAS cells exposed with CA $(0,2.5,5,10,15$ and $20 \mu \mathrm{M})$ for 5 days were measured using a colony formation assay. ${ }^{*}, p<0.05$; ${ }^{*}, p<0.01$ vs. control (line 1), (Mean $\pm \mathrm{SE}, n=3$ ). Control: untreated cells.

\subsection{Effect of CA on Cell Cycle Distribution and Apoptosis Induction in Human HSC3 and SAS Cells}

Human HSC3 and SAS cells were exposed to various concentrations $(0,2.5,5$ and $10 \mu \mathrm{M})$ of CA for $24 \mathrm{~h}$. Cell cycle distribution and apoptosis induction were further analysed using a flow cytometry assay. The results revealed that CA treatment $(0,2.5,5$ and $10 \mu \mathrm{M})$ did not influence the regulation of cell arrest at any phase (Figure 2A). Moreover, the induction of apoptosis using CA was not observed in HSC3 and SAS cells through flow cytometry detection (Figure 2B). Therefore, CA does not affect the cell cycle distribution and induction of apoptosis in human OSCC cells based on the aforementioned results.

\subsection{CA Suppresses Cell Migration and Invasion in Human OSCC Cells}

To investigate the influence of $\mathrm{CA}$ in regulating cellular migration and invasion activity in human OSCC cells, human HSC 3 and SAS cells were exposed to various concentrations of $\mathrm{CA}(0,2.5,5$ and $10 \mu \mathrm{M})$ for $24 \mathrm{~h}$ and subjected to cellular migration and invasion assays. The findings showed that CA significantly suppresses the cell migration and invasion activity of human HSC3 and SAS cells dose-dependently (Figure 3). 


\section{A}
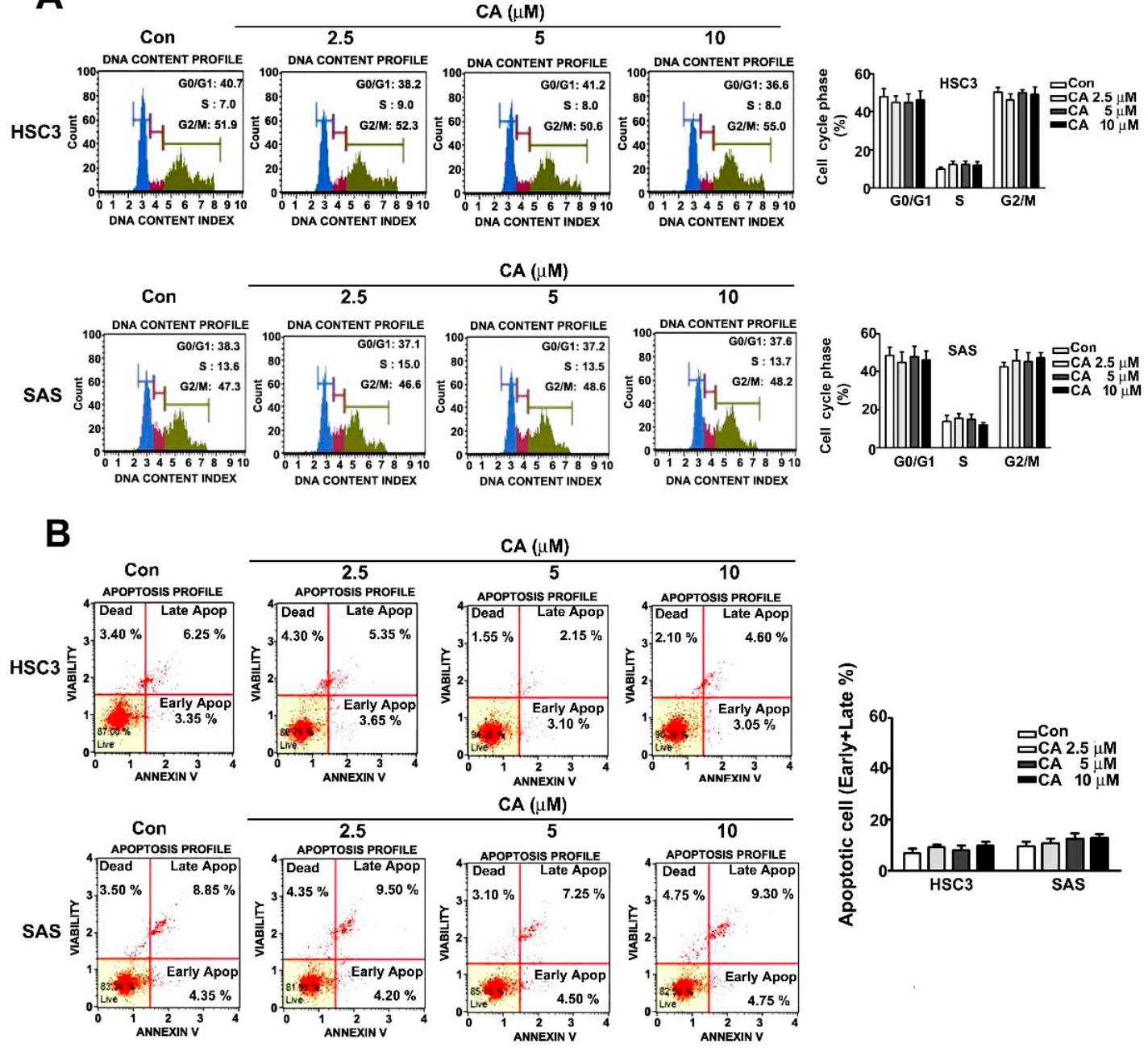

Figure 2. Effect of CA on cell cycle arrest and apoptosis induction in human HSC3 and SAS OSCC cells. (A) The regulation of cell cycle distribution was analysed using PI staining by flow cytometry. (B) Apoptosis induction in human HSC3 and SAS cells exposed to various concentrations $(0,2.5,5$ and $10 \mu \mathrm{M})$ of CA by Annexin V/PI staining through flow cytometry. (Mean $\pm \mathrm{SE}, n=3$ ). Control: untreated cells.
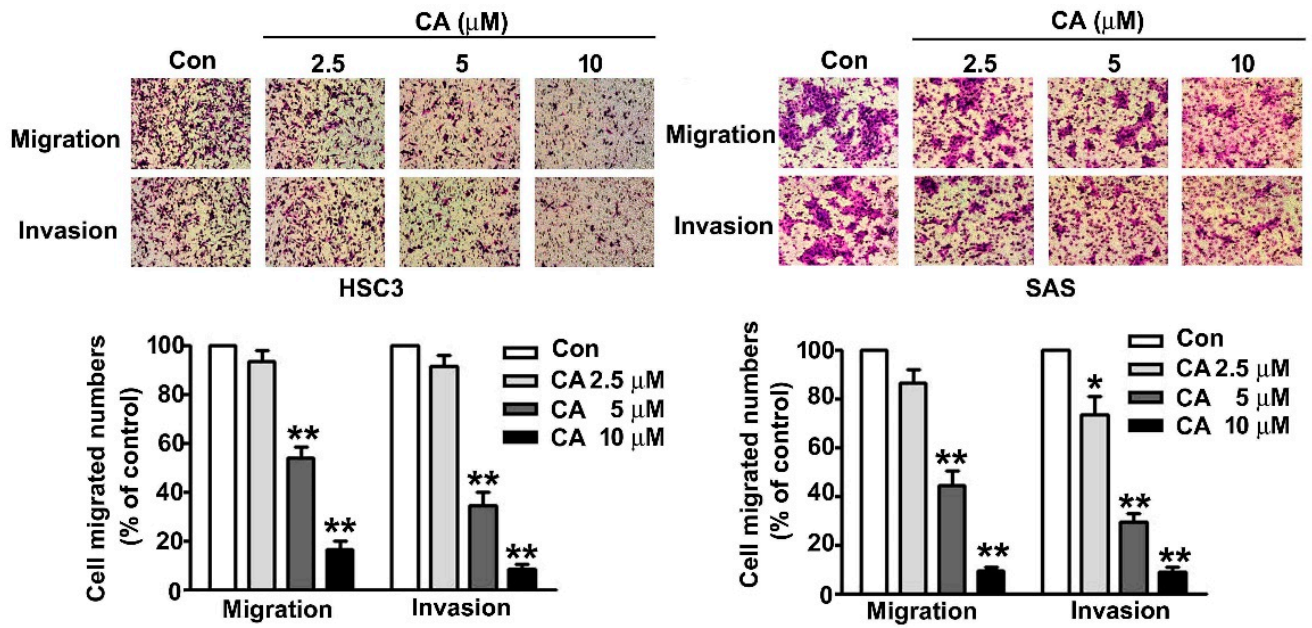

Figure 3. Effect of CA on cell migration and invasion of human HSC3 and SAS OSCC cells. Human HSC 3 and SAS cells were treated with various concentrations of CA $(0,2.5,5$ and $10 \mu \mathrm{M})$ for $24 \mathrm{~h}$, and then, capacities of cellular migration and invasion were measured. ${ }^{*}, p<0.05,{ }^{* *}, p<0.01$ vs. control (line 1 ), (Mean $\pm \mathrm{SE}, n=3$ ). Control: untreated cells. Scale bars: $50 \mu \mathrm{m}$. 


\subsection{CA Inhibits MMP1 Expression and Cell Invasion in Human HSC3 and SAS OSCC Cells}

MMP1 has been reported to act as a critical factor in accelerating cancer progression by upregulating the capacity of migration and invasion in cancer cells [12]. We treated both human HSC3 and SAS cells with various concentrations of CA $(0,2.5,5,10$ or $20 \mu \mathrm{M})$ for $24 \mathrm{~h}$ and identified the influence of CA on the protein and mRNA expressions of MMP1 in these cells using immunoblotting and RT-qPCR assays. The results revealed that CA significantly reduced the protein and mRNA levels of MMP1 in HSC3 and SAS cells (Figure 4A,B). Higher MMP1 mRNA expression of human OSCC tissues than that of normal oral tissues was further confirmed using the GEPIA database (Figure 4C). Furthermore, patients with OSCC with high MMP1 expression had shorter overall survival (OS) (HR $=1.39,95 \% \mathrm{CI}$ 1.04-1.87, $p=0.027$ ) than those with low MMP1 expression (Figure 4D). We further examined the synergistic influence of both CA and siMMP1 on the MMP1 expression, and migration and invasion activity in human HSC 3 and SAS cells. The results revealed that an individual treatment of CA $(10 \mu \mathrm{M})$ or MMP1 siRNA (siMMP1; $100 \mathrm{nM}$ ) significantly downregulated the MMP1 protein expression, and migration and invasion activity in human HSC3 cells. The scramble siRNA did not affect the MMP1 expression (Supplementary Figure S2A). Additionally, the co-administration of CA (10 $\mu \mathrm{M})$ and siMMP1 (100 nM) showed a greater synergistic inhibitory effect on MMP1 expression and motility activity in human HSC3 cells (Figure 4E,F).Transfection of the scramble siRNA did not affect the migration and invasion ability of HSC3 cells (Supplementary Figure S2B).

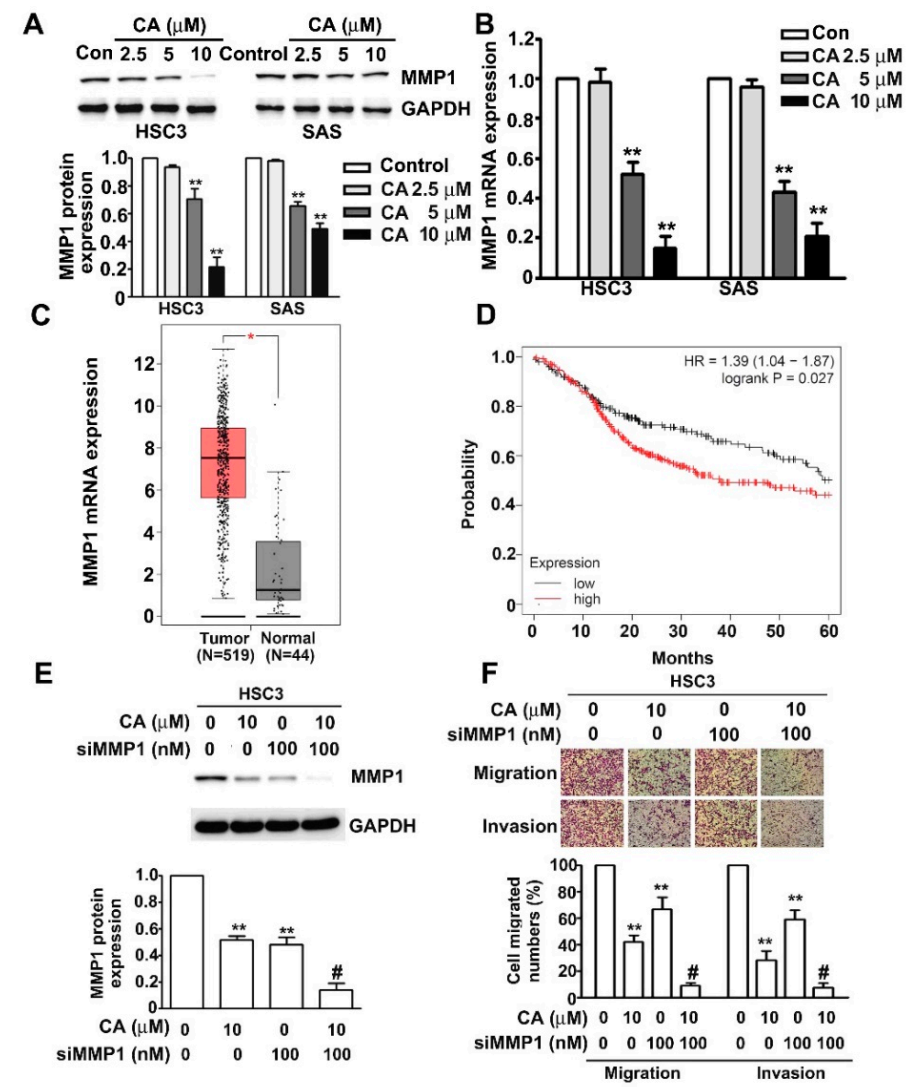

Figure 4. Effect of CA on MMP1 expression and cell invasion in human HSC3 and SAS OSCC cells. (A,B) Human HSC3 and SAS cells were treated with various concentrations of CA $(0,2.5,5,10$ or $20 \mu \mathrm{M})$ for $24 \mathrm{~h}$, after which the protein and mRNA expression of MMP1 was measured via immunoblotting and qRT-PCR analysis. (C) MMP1 mRNA expression in the matched OSCC tissues and normal tissues was validated from the GEPIA databases. T: Tumour tissue $(n=519) ; \mathrm{N}$ : Normal tissue $(n=44) .{ }^{*}, p<0.05$ versus normal tissue. (D) The red line indicates high MMP1 expression, and the black line indicates low MMP1 expression. (E,F) Human HSC3 cells were treated with CA (10 $\mu \mathrm{M})$, siMMP1 $(100 \mathrm{nM})$ or CA $(10 \mu \mathrm{M})$ plus siMMP1 $(100 \mathrm{nM})$; then, MMP1 protein expression, migration and invasion were measured. GAPDH as a protein-loading control. ${ }^{* *}, p<0.01$ versus control (line 1$), \#, p<0.05$ vs. CA (line 2 ) or siMMP1 (line 3$)$. Control: untreated cells. Scale bars: $50 \mu \mathrm{m}$. 


\subsection{ERK1/2 Pathway Mediates CA-Downregulated MMP1 Expression, Cell Migration and Invasion in Human HSC3 Cells}

The ERK1/2 pathway plays an essential role in mediating tumour progression [12,17]. Thus, we examined the influence of CA on ERK1/2 activation of human HSC3 OSCC cells treated with various concentrations of CA $(0,2.5,5$ or $10 \mu \mathrm{M})$. The results revealed that CA significantly inhibits ERK1/2 phosphorylation dose-dependently (Figure 5A). ERK2 siRNA (siERK2) and U0126 (ERK1/2 specific inhibitor) were further used to confirm the ERK1/2-mediated inhibitory effect on MMP1 expression and invasive motility in human HSC 3 cells. The synergistically inhibitory effects of CA $(10 \mu \mathrm{M})$ plus siERK2 $(50 \mu \mathrm{M})$ or CA $(10 \mu \mathrm{M})$ plus U0126 $(50 \mu \mathrm{M})$ co-treatment on MMP1 expression and metastatic activity were then measured in human HSC3 cells (Figure 5B-E). The scramble siRNA did not affect the ERK2 expression and cell migration/invasion in HSC3 cells (Supplementary Figure S2C,D).The results indicated that the ERK1/2 pathway plays a critical role in mediating CA-downregulated MMP1 expression and metastasis in human $\mathrm{HSC} 3$ cells.

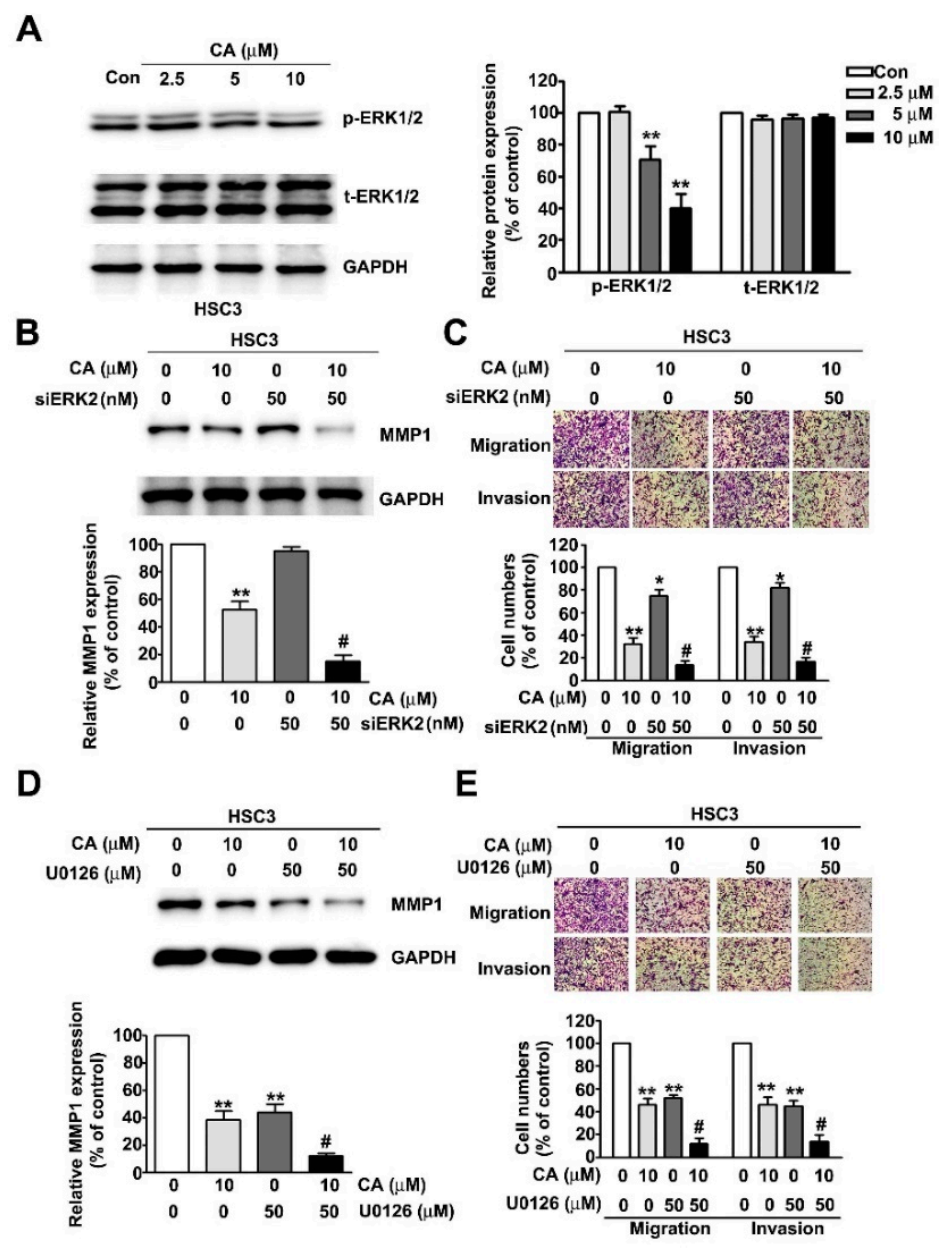

Figure 5. ERK1/2 pathway participation in CA-downregulated MMP1 expression, cell migration and invasion in human HSC3 cells. (A) Human HSC3 cells were treated with various concentrations of CA $(0,2.5,5$ or $10 \mu \mathrm{M})$, after which phospho-ERK1/2 and total-ERK1/2 protein levels were measured via immunoblotting analysis. (B,C) Human HSC3 cells were treated with CA $(10 \mu \mathrm{M})$, siERK2 $(50 \mathrm{nM})$ or CA $(10 \mu \mathrm{M})$ plus siERK2 $(50 \mathrm{nM})$; and then MMP1 protein level, migration and invasion were further measured. (D,E) Human HSC3 cells were treated with CA (10 $\mu$ M), U0126 (specific ERK1/2 inhibitor; $50 \mu \mathrm{M})$ or CA $(10 \mu \mathrm{M})$ plus U0126 $(50 \mu \mathrm{M})$, following which MMP1 protein level, migration and invasion were further measured. GAPDH was used as a protein loading control. Control: untreated cells and scrambled siRNA-transfected cells (for siRNA transfection). ${ }^{*}, p<0.05 ;{ }^{* *}, p<0.01$ versus control (line 1); \#, $p<0.05$ versus CA (line 2) or siERK2, U0126 (line 3) (Mean $\pm \mathrm{SE}, n=3$ ). Control: untreated cells. Scale bars: $50 \mu \mathrm{m}$. 


\section{Discussion}

OSCC is currently the fourth leading cause of cancer-related deaths among men in Taiwan. OSCC is life threatening because the five-year survival rate of total OSCC patients is approximately $50 \%$ [18]. Therefore, it is crucial to identify the potential treatment strategies and anticancer drugs for OSCC prevention and therapy. Natural phytochemicals are worth developing because compounds of plant origin have less toxicity and a more potential biological activity against cancer progression. CA is a natural pentacyclic triterpenoid and can be extracted from the leaves of Eriobotrta japonica [19] and from the fruit of Cratoegus pinnatifida var. Psilosa [20]. In this study, the results were as follows: (1) CA did not reduce cell growth and colony formation by regulating cell cycle arrest or apoptosis induction in human OSCC cells; (2) CA significantly inhibits cell migration and invasion by downregulating MMP1 expression; (3) MMP1 is highly expressed in OSCC tissues and is positively correlated with shorter OS of patients with OSCC; (4) the co-administration of CA and siMMP1 synergistically inhibits MMP1 expression and the invasive motility activity of human OSCC cells; and (5) the ERK1/2 pathway mediates CA-downregulated MMP1 expression, cell migration and invasion in human OSCC cells. Collectively, these findings indicate that CA inhibits invasive motility by downregulating the ERK1/2-MMP1 axis. Therefore, CA could rather potentially be a novel and interesting natural phytochemical agent against OSCC.

The poor prognosis and high mortality of OSCC are primarily due to the highly invasive motility activity in cancer cells. ECM remodelling via MMP activation contributes to the spread and invasion of malignant cells by disrupting the interaction between cells and the ECM [10]. Immunohistochemistry with the use of a tissue microarray revealed that MMP1 is overexpressed in primary nodular melanoma [21]. MMP1 overexpression by silencing miR-202-3p promotes breast cancer cells to transmigrate through the brain endothelium [13]. The activation of COX2-MMP1 signalling via miR-101-3p loss promotes the transmigration of metastatic breast cancer cells through brain endothelium [22]. MMP1 drives tumour progression in large cell carcinoma of the lung through fibroblast senescence [11]. Thus, the inhibition of ECM remodelling by targeting MMP1 activation is considered a critical step in cancer therapy. Interferon regulatory factor 2 inhibits gastric cancer invasion and migration by downregulating MMP1 [23]. The knockdown of MMP1 inhibits the progression of colorectal cancer by suppressing the PI3K/Akt/c-myc signalling pathway and epithelial-mesenchymal transition [24]. miR-361-5p inhibits the glycolysis, proliferation, and invasion of breast cancer cells by targeting MMP1 [25]. The reduction in PKC alpha expression inhibits cell proliferation, migration and invasion in human malignant hepatocellular carcinoma (HCC) through downregulating MMP1 expression [26]. Licochalcone A inhibits the migration and invasion of human lung cancer cells via the downregulation of MMP1 expression [27]. Praeruptorin A inhibited the migration and invasion of human HCC cells while downregulating the expression of MMP1 [12]. The expression of MMP1 is upregulated in oral lichen planus, dysplasia, squamous cell carcinoma, and lymph node metastasis [28]. The relative mRNA level of MMP1 in the OSCC tissues has a 3.26-fold increase in comparison with that in paired normal tissues [29]. The elevated MMP1 protein expression is associated with a higher histopathological grade of OSCC [30]. Tight junction protein claudin-1 enhances the invasive activity of OSCC by promoting the cleavage of a laminin-5 gamma2 chain via MMP1 [31]. S100A14 regulates the invasive potential of OSCC-derived cell lines in vitro by modulating the expression of MMP1 [32]. MMP1 $3^{\prime} U T R$ accelerates the proliferation and migration of OSCC by sponging miR-188-5p to upregulate the expression of SOX4 and CDK4 [33]. This study observed that MMP1 is highly expressed in OSCC tissues compared with that in normal oral tissues. A high expression of MMP1 was positively correlated with a shorter OS rate of patients with OSCC. MMP1 downregulation using CA or CA cotreatment with siMMP1 significantly inhibits migration and invasion in human OSCC cells.

ERK1/2 is a member of mitogen-activated protein kinases and is reported to play a pivotal role in regulating tumorigenic processes in vitro and in vivo, including cellu- 
lar proliferation, apoptosis, angiogenesis, lymphangiogenesis and metastasis. ERK1/2 is showed to mediate fisetin-induced apoptosis and anticancer effects in human cervical cancer HeLa cells [34]. The inhibition of ERK1/2 via U0126 or transfection with the siERK plasmid significantly abolishes the fisetin-inhibited migration and invasion by activating the ERK1/2 pathway [35]. ERK1/2 blocking inhibits MMP-2-mediated cell motility and further enhances the anti-invasive ability of tricetin in glioblastoma multiforme cells [36]. Praeruptorin A significantly inhibits the growth and invasion of human cervical cancer cells by suppressing ERK1/2 signalling [17]. Epigallocatechin gallate could inhibit the migration of human uveal melanoma cells via the downregulation of ERK1/2 phosphorylation [37]. Kaempferol inhibits cell migration by targeting ERK1/2 signalling in human retinal pigment epithelial cells [38]. In addition, ERK1/2 mediates the antimetastatic activity of $\beta$-mangostin against human hepatocellular carcinoma cells [39]. This study observed that the inhibition of ERK1/2 signalling via siERK2 or U0126 significantly suppressed MMP1 expression, migration and invasion in human OSCC cells. The co-administration of CA plus siERK2 or CA plus U0126 showed a greater synergistic inhibitory effect on MMP1 expression and cellular motility activity.

Potential plant-derived bioactive compounds with less toxicity and more therapeutic effects are identified as auxiliary anticancer therapy for improving the outcome of patients with cancer. CA decreases intracellular $\beta$-catenin levels and suppresses APC-mutated colon cancer cell growth [40]. Additionally, CA administration reduces the number of infiltrating lymphocytes in tumour tissues. A significant immunosuppressive effect of myeloid-derived suppressor cells in tumour-bearing mice was abrogated using CA in ex vivo analysis [41]. CA exhibits antiangiogenic and antilymphangiogenic effects by reducing the proliferation and migration of human umbilical vein endothelial cells stimulated using angiopoietin- 1 on the in vitro model. CA decreases the final tumour volume and the blood and lymphatic vessel densities of tumours, indicating that it suppresses in vivo angiogenesis and lymphangiogenesis on an in vivo CT-26 colon carcinoma animal model [42]. CA inhibits colorectal cancer cell growth via directly targeting HER2 and HER3 heterodimerisation [43]. CA treatment reduces tumourigenesis through translocating and deactivating YAP from the nucleus in hepatocellular carcinoma [16]. CA inhibits VEGFR2 kinase activity, disrupts tubulin structure and impairs human lung adenocarcinoma A549 cell proliferation in a xenograft mouse model [44]. CA inhibits cell growth and induces ER stress-dependent apoptosis in human prostate cancer PC-3 and DU145 cell lines and decelerates tumour growth in a xenograft model [15]. CA treatment dose-dependently induces cytotoxicity, cell cycle arrest and apoptosis in human retinoblastoma Y-79 cells by disrupting MELK-FM1 signalling [45]. CA induces non-apoptotic cell death in other renal cancer cells (ACHN and A498), breast cancer cells (MDA-MB231) and hepatocellular carcinoma cells (SK-Hep1 and Huh7) through the generation of lipid reactive oxygen species production [46]. CA is reported to have a lowering effect on postprandial blood sugar levels in human studies and to improve insulin resistance conditions $[47,48]$. Some evidence has shown that no adverse effects about CA used in optimal dosage are reported in clinical trials and animal study. CA may resolve metabolic syndrome and may provide health benefits $[47,49]$. Thus, $\mathrm{CA}$ is considered as a potential compound against OSCC treatment.

\section{Materials and Methods}

\subsection{Chemical Reagents and Antibodies}

Corosolic acid (CA: formula: $\mathrm{C} 30 \mathrm{H} 48 \mathrm{O} 4)$ was purchased from ChemFaces company (Wuhan, Hubei, China). MTT and DMSO were obtained from Sigma-Aldrich (St. Louis, MO, USA). Primary antibodies against phospho-EKR1/2, total-ERK1/2, MMP1 and GAPDH were purchased from Cell Signalling Technology (Danvers, MA, USA). The scramble siRNA and siRNA-MMP1 (siMMP1) were obtained from Santa Cruz Biotechnology (Santa Cruz, CA, USA). The scramble siRNA and siRNA-ERK2 (siERK2) was purchased from ALLBio (Taipei, Taiwan). 


\subsection{Cell Culture}

Human HSC3 (Human tongue squamous carcinoma cell line) and SAS (Human tongue squamous carcinoma cell line) were a gift from Prof. Shun-Fa Yang (Institute of Medicine, Chung Shan Medical University, Taichung, Taiwan). HSC3 and SAS cells were cultured in DMEM/F-12 medium (Life Technologies, Grand Island, NY, USA) containing 10\% foetal bovine serum, $2 \mathrm{mM}$ glutamine and $100 \mathrm{U} / \mathrm{mL}$ of penicillin-streptomycin (Invitrogen Life Technologies, Carlsbad, CA, USA). All cell cultures were maintained in a humidified incubator with $5 \% \mathrm{CO}_{2}$ at $37^{\circ} \mathrm{C}$. An origin stock reagent was prepared for $\mathrm{CA}(50 \mathrm{mM})$ and dissolved in dimethyl sulfoxide (DMSO) solution. The cell experiment used final DMSO concentrations for the highest concentration of CA at $0.04 \%$ DMSO.

\subsection{Cell Viability Assay}

To determine the effect of CA on cell viability, human OSCC cells were seeded with a density of $9 \times 10^{4} /$ well (HSC3) or $1.2 \times 10^{5} /$ well (SAS) cells per well in 24-well plates (Greiner Bio-One, Frickenhausen, Germany) and treated with various concentrations of CA for 24 or $48 \mathrm{~h}$. The cells were then washed with PBS and incubated at a final concentration of $0.5 \mathrm{mg} / \mathrm{mL}$ of MTT per well at $37^{\circ} \mathrm{C}$ in $5 \% \mathrm{CO}_{2}$ for $4 \mathrm{~h}$. Cell viability was measured at $563 \mathrm{~nm}$ using a Multiskan MS ELISA reader (Labsystems, Helsinki, Finland).

\subsection{Colony Formation Assay}

Colony formation was performed as described in previous studies [50]. Human HSC3 and SAS cells were seeded in six-well plates $\left(1 \times 10^{4} /\right.$ well $)$ and treated with various concentrations of CA for 5 days. More than 100 colonies were stained with $0.5 \%$ crystal violet solution for $30 \mathrm{~min}$ at room temperature and analysed. Three independent experiments were performed.

\subsection{Annexin V/PI Staining via Flow Cytometry Analysis}

Cell cycle assay was performed as described in a previous study [51]. Human HSC3 and SAS cells $\left(5 \times 10^{5} /\right.$ well) were treated with various concentrations of CA for $24 \mathrm{~h}$ and then fixed with $75 \%$ ice ethanol overnight. These fixed cells were stained with PI reagent for 20 min. Cell DNA content was measured through flow cytometry using the Muse Cell Analyser (Merck Millipore, Burlington, MA, USA). The outcome data were further analysed using the Muse Cell Analyser. An apoptosis assay was performed as previously described [52]. After the HSC3 and SAS cells were treated with various concentrations of $\mathrm{CA}$ for $24 \mathrm{~h}$, the cells were harvested and apoptosis was measured using the Muse Annexin $\mathrm{V}$ and Dead Cell Assay Kit (Merck Millipore). In brief, the collected cells were incubated with $5 \mu \mathrm{L}$ of Annexin V-FITC and $5 \mu \mathrm{L}$ of PI reagents at room temperature in darkness for $15 \mathrm{~min}$. The apoptotic cell population was then analysed using the Muse Cell Analyser (Merck Millipore).

\section{6. siRNA Transfection}

The siRNA transfection assay were performed as previously as published report [12] For the knockdown assay, $4 \times 10^{5}$ of OSCC cells were seeded into a $6 \mathrm{~cm}$ culture dish overnight. Using the RNAiMAX reagent (Thermo Fisher Scientific, MA, USA), scramble siRNA or siRNA-MMP1 (siMMP1)/siRNA-ERK2 (siERK2) were mixed in serum free medium for $6 \mathrm{~h}$. A fresh culture medium (20\% FBS) was then added and incubated in a $37^{\circ} \mathrm{C}$. After $24 \mathrm{~h}$, it was treated with or without $\mathrm{CA}(10 \mu \mathrm{M})$ for another $24 \mathrm{~h}$ and detected for subsequent experiments.

\subsection{Immunoblotting Analysis}

Immunoblotting analysis was performed as described previously [51]. Briefly, proteins were harvested from the human HSC3 and SAS cells lysed with a lysis buffer. Equal amounts of total protein $(20 \mu \mathrm{g})$ from each experimental group were subjected to $10-12 \%$ SDS-PAGE for protein separation and then transferred onto a PVDF membrane (Life 
Technologies, Carlsbad, CA, USA). Next, the membranes were blocked with 5\% non-fat dry milk in Tris-buffered saline with Tween-20 buffer. The blocked membranes were further incubated with primary target antibodies and subsequently with secondary antibodies to detect antibody-bound protein bands using the Luminescent Image Analyser (LAS 4000 mini, GE Healthcare Bio-Sciences, Pittsburgh, PA, USA).

\subsection{Migration and Invasion Assay}

Cellular migration and invasion were analysed as described previously [51]. In brief, HSC 3 and SAS cells $\left(5 \times 10^{5} /\right.$ well) were seeded onto filter inserts (pore size: $8 \mu \mathrm{m}$ ) that were pre-coated with or without Matrigel $(0.5 \mathrm{mg} / \mathrm{mL})$ for cellular invasion assay and migration assays, respectively. Cells migrating or invading the lower side of the filter insert were stained with 5\% Giemsa reagent and counted at $200 \times$ magnification. Four microscopic fields were counted for each filter, and each experimental group was repeated three times.

\subsection{Clinical Data Analysis by TCGA Database}

The expression data from human OSCC tissues and normal oral tissues from TCGA and the GTEx projects were obtained by using a Gene Expression Profiling Interactive Analysis (GEPIA) database (http:/ / gepia.cancer-pku.cn/, accessed on 1 July 2021), which can analyse the MMP1 expression of tumour and normal tissues. The Overall survival (OS) plots module was applied to examine the survival rate with high or low expression of MMP1 in human OSCC tissues by using the Kaplan-Meier curves (https: / / kmplot.com/analysis/, accessed on 1 July 2021).

\subsection{Quantitative Reverse Transcription PCR ( $q R T-P C R$ )}

The RNA extraction and qRT-PCR method were performed on previous experiments [12]. The primers used for qRT-PCR were as follows: MMP1: forward primer, 5'-CTT GCT CAT GCT TTT CGA CC-3'; reverse primer; $5^{\prime}$-TCC GGG TAG AAG GGA TTT GTG-3'; Glyceraldehyde 3-phosphate dehydrogenase (GAPDH): forward primer, 5'-CAT CAT CCC TGC CTC TAC TG- $3^{\prime}$; and reverse primer, $5^{\prime}$-GCC TGC TTC ACC ACC TTC- $3^{\prime}$ (MISSION BIOTECH, Taipei, Taiwan).

\subsection{Statistical Analysis}

Each experiment was repeated at least three times. The results are presented as the mean \pm standard error. One-way analysis of variance followed by Dunnett post hoc test and statistical comparisons were conducted using Student's $t$-test and SPSS (v.18.0). Significance was defined at the $p<0.05$ or 0.01 levels.

\section{Conclusions}

In this study, CA was first reported to significantly inhibit cell migration and invasion of human OSCC cells in vitro. Analyses from the molecular mechanism revealed that CA suppressed the metastasis of OSCC cells through inhibition of the ERK1/2-MMP1 axis.

Supplementary Materials: The following are available online at https: / www.mdpi.com/article/10 $.3390 /$ ijms22168641/s1, Figure S1: DMSO (0.04\%) in culture medium did not affect the cell viability of HSC3 and SAS cells. Figure S2: Effect of scramble siRNA, siMMP1 and siERK2 on MMP1/ERK2 protein expressions and cell migration/invasion in HSC3 cells

Author Contributions: Conceptualization, J.-L.C., Y.-H.H. and C.-Y.L.; methodology, P.-H.W., C.-W.L. and Y.-H.H.; software, Y.-H.H. and P.-H.W.; validation, C.-W.L., P.-H.W. and T.-H.Y.; formal analysis, J.-L.C. and P.-H.W.; investigation, F.-J.Y. and P.-H.W.; resources, T.-H.Y. and Y.-H.H.; data curation, C.-J.L. and Y.-H.H.; writing-original draft preparation, C.-J.L. and Y.-H.H.; writing-review and editing, J.-L.C., C.-Y.L. and Y.-H.H.; visualization, J.-L.C. and C.-Y.L.; supervision, F.-J.Y., J.-L.C. and C.-Y.L.; project administration, C.-Y.L., Y.-H.H. and C.-W.L.; funding acquisition, J.-L.C. and C.-Y.L. All authors have read and agreed to the published version of the manuscript. 
Funding: This research was funded by Chung-Kang Branch, Cheng-Ching General Hospital Research Fund (CH10900245A) and supported partially by Kaohsiung Medical University Hospital (KMUH109M901) and Kaohsiung Medical University Research Center Grant (KMU-TC109A02-3).

Institutional Review Board Statement: Not applicable.

Informed Consent Statement: Not applicable.

Data Availability Statement: Not applicable.

Conflicts of Interest: The authors declare no conflict of interest.

\section{References}

1. Tsantoulis, P.K.; Kastrinakis, N.G.; Tourvas, A.D.; Laskaris, G.; Gorgoulis, V.G. Advances in the biology of oral cancer. Oral Oncol. 2007, 43, 523-534. [CrossRef]

2. Gasche, J.A.; Goel, A. Epigenetic mechanisms in oral carcinogenesis. Future Oncol. 2012, 8, 1407-1425. [CrossRef]

3. Scully, C.; Porter, S. ABC of oral health. Oral cancer. BMJ 2000, 321, 97-100. [CrossRef]

4. da Silva, S.D.; Ferlito, A.; Takes, R.P.; Brakenhoff, R.H.; Valentin, M.D.; Woolgar, J.A.; Bradford, C.R.; Rodrigo, J.P.; Rinaldo, A.; Hier, M.P.; et al. Advances and applications of oral cancer basic research. Oral Oncol. 2011, 47, 783-791. [CrossRef]

5. Bacac, M.; Stamenkovic, I. Metastatic cancer cell. Annu. Rev. Pathol. 2008, 3, 221-247. [CrossRef]

6. Valastyan, S.; Weinberg, R.A. Tumor metastasis: Molecular insights and evolving paradigms. Cell 2011, 147, 275-292. [CrossRef]

7. Liotta, L.A.; Stetler-Stevenson, W.G. Tumor invasion and metastasis: An imbalance of positive and negative regulation. Cancer Res. 1991, 51, 5054s-5059s.

8. $\quad$ Lin, C.W.; Chou, Y.E.; Chiou, H.L.; Chen, M.K.; Yang, W.E.; Hsieh, M.J.; Yang, S.F. Pterostilbene suppresses oral cancer cell invasion by inhibiting MMP-2 expression. Expert Opin. Ther. Targets 2014, 18, 1109-1120. [CrossRef] [PubMed]

9. Yang, S.F.; Lee, W.J.; Tan, P.; Tang, C.H.; Hsiao, M.; Hsieh, F.K.; Chien, M.H. Upregulation of miR-328 and inhibition of CREBDNA-binding activity are critical for resveratrol-mediated suppression of matrix metalloproteinase- 2 and subsequent metastatic ability in human osteosarcomas. Oncotarget 2015, 6, 2736-2753. [CrossRef] [PubMed]

10. Pittayapruek, P.; Meephansan, J.; Prapapan, O.; Komine, M.; Ohtsuki, M. Role of Matrix Metalloproteinases in Photoaging and Photocarcinogenesis. Int. J. Mol. Sci. 2016, 17, 868. [CrossRef] [PubMed]

11. Gabasa, M.; Radisky, E.S.; Ikemori, R.; Bertolini, G.; Arshakyan, M.; Hockla, A.; Duch, P.; Rondinone, O.; Llorente, A.; Maqueda, M.; et al. MMP1 drives tumor progression in large cell carcinoma of the lung through fibroblast senescence. Cancer Lett. 2021, 507, 1-12. [CrossRef]

12. Yu, C.L.; Yu, Y.L.; Yang, S.F.; Hsu, C.E.; Lin, C.L.; Hsieh, Y.H.; Chiou, H.L. Praeruptorin A reduces metastasis of human hepatocellular carcinoma cells by targeting ERK/MMP1 signaling pathway. Environ. Toxicol. 2021, 36, 540-549. [CrossRef]

13. Harati, R.; Hafezi, S.; Mabondzo, A.; Tlili, A. Silencing miR-202-3p increases MMP-1 and promotes a brain invasive phenotype in metastatic breast cancer cells. PLoS ONE 2020, 15, e0239292. [CrossRef]

14. Zhao, J.; Zhou, H.; An, Y.; Shen, K.; Yu, L. Biological effects of corosolic acid as an anti-inflammatory, anti-metabolic syndrome and anti-neoplasic natural compound. Oncol. Lett. 2021, 21, 84. [CrossRef]

15. Ma, B.; Zhang, H.; Wang, Y.; Zhao, A.; Zhu, Z.; Bao, X.; Sun, Y.; Li, L.; Zhang, Q. Corosolic acid, a natural triterpenoid, induces ER stress-dependent apoptosis in human castration resistant prostate cancer cells via activation of IRE-1/JNK, PERK/CHOP and TRIB3. J. Exp. Clin. Cancer Res. 2018, 37, 210. [CrossRef]

16. Jia, M.; Xiong, Y.; Li, M.; Mao, Q. Corosolic Acid Inhibits Cancer Progress Through Inactivating YAP in Hepatocellular Carcinoma. Oncol. Res. 2020, 28, 371-383. [CrossRef]

17. Wu, M.H.; Lin, C.L.; Chiou, H.L.; Yang, S.F.; Lin, C.Y.; Liu, C.J.; Hsieh, Y.H. Praeruptorin A Inhibits Human Cervical Cancer Cell Growth and Invasion by Suppressing MMP-2 Expression and ERK1/2 Signaling. Int. J. Mol. Sci. 2017, 19, 10. [CrossRef]

18. Chen, Y.S.; Hung, T.W.; Su, S.C.; Lin, C.L.; Yang, S.F.; Lee, C.C.; Yeh, C.F.; Hsieh, Y.H.; Tsai, J.P. MTA2 as a Potential Biomarker and Its Involvement in Metastatic Progression of Human Renal Cancer by miR-133b Targeting MMP-9. Cancers (Basel) $2019,11,1851$. [CrossRef]

19. Wang, Q.; Sun, Q.; Ma, X.; Rao, Z.; Li, H. Probing the binding interaction of human serum albumin with three bioactive constituents of Eriobotrta japonica leaves: Spectroscopic and molecular modeling approaches. J. Photochem. Photobiol. B 2015, 148, 268-276. [CrossRef]

20. Ahn, K.S.; Hahm, M.S.; Park, E.J.; Lee, H.K.; Kim, I.H. Corosolic acid isolated from the fruit of Crataegus pinnatifida var. psilosa is a protein kinase $C$ inhibitor as well as a cytotoxic agent. Planta Med. 1998, 64, 468-470. [CrossRef]

21. Zamolo, G.; Grahovac, M.; Zauhar, G.; Vucinic, D.; Kovac, L.; Brajenic, N.; Grahovac, B. Matrix metalloproteinases MMP-1, MMP-2, and MMP-13 are overexpressed in primary nodular melanoma. J. Cutan Pathol. 2020, 47, 139-145. [CrossRef] [PubMed]

22. Harati, R.; Mohammad, M.G.; Tlili, A.; El-Awady, R.A.; Hamoudi, R. Loss of miR-101-3p Promotes Transmigration of Metastatic Breast Cancer Cells through the Brain Endothelium by Inducing COX-2/MMP1 Signaling. Pharmaceuticals (Basel) 2020, 13, 144. [CrossRef]

23. Chen, Y.J.; Liang, L.; Li, J.; Wu, H.; Dong, L.; Liu, T.T.; Shen, X.Z. IRF-2 Inhibits Gastric Cancer Invasion and Migration by Down-Regulating MMP-1. Dig. Dis. Sci. 2020, 65, 168-177. [CrossRef] [PubMed] 
24. Wang, K.; Zheng, J.; Yu, J.; Wu, Y.; Guo, J.; Xu, Z.; Sun, X. Knockdown of MMP1 inhibits the progression of colorectal cancer by suppressing the PI3K/Akt/cmyc signaling pathway and EMT. Oncol. Rep. 2020, 43, 1103-1112. [CrossRef]

25. Ma, F.; Zhang, L.; Ma, L.; Zhang, Y.; Zhang, J.; Guo, B. MiR-361-5p inhibits glycolytic metabolism, proliferation and invasion of breast cancer by targeting FGFR1 and MMP-1. J. Exp. Clin. Cancer Res. 2017, 36, 158. [CrossRef]

26. Wu, T.T.; Hsieh, Y.H.; Hsieh, Y.S.; Liu, J.Y. Reduction of PKC alpha decreases cell proliferation, migration, and invasion of human malignant hepatocellular carcinoma. J. Cell. Biochem. 2008, 103, 9-20. [CrossRef]

27. Huang, H.C.; Tsai, L.L.; Tsai, J.P.; Hsieh, S.C.; Yang, S.F.; Hsueh, J.T.; Hsieh, Y.H. Licochalcone A inhibits the migration and invasion of human lung cancer cells via inactivation of the Akt signaling pathway with downregulation of MMP-1/-3 expression. Tumor Biol. 2014, 35, 12139-12149. [CrossRef]

28. Sutinen, M.; Kainulainen, T.; Hurskainen, T.; Vesterlund, E.; Alexander, J.P.; Overall, C.M.; Sorsa, T.; Salo, T. Expression of matrix metalloproteinases (MMP-1 and -2) and their inhibitors (TIMP-1, -2 and -3) in oral lichen planus, dysplasia, squamous cell carcinoma and lymph node metastasis. Br. J. Cancer 1998, 77, 2239-2245. [CrossRef]

29. Lu, X.Z.; Zou, Y.G.; Yin, X.M.; Chen, W.T.; Zhang, C.P. Expression of MMP1 mRNA in oral squamous cell carcinoma and paired normal tissues. Nan Fang Yi Ke Da Xue Xue Bao 2008, 28, 1362-1364.

30. George, A.; Ranganathan, K.; Rao, U.K. Expression of MMP-1 in histopathological different grades of oral squamous cell carcinoma and in normal buccal mucosa-An immunohistochemical study. Cancer Biomark. 2010, 7, 275-283. [CrossRef]

31. Oku, N.; Sasabe, E.; Ueta, E.; Yamamoto, T.; Osaki, T. Tight junction protein claudin-1 enhances the invasive activity of oral squamous cell carcinoma cells by promoting cleavage of laminin-5 gamma2 chain via matrix metalloproteinase (MMP)-2 and membrane-type MMP-1. Cancer Res. 2006, 66, 5251-5257. [CrossRef] [PubMed]

32. Sapkota, D.; Bruland, O.; Costea, D.E.; Haugen, H.; Vasstrand, E.N.; Ibrahim, S.O. S100A14 regulates the invasive potential of oral squamous cell carcinoma derived cell-lines in vitro by modulating expression of matrix metalloproteinases, MMP1 and MMP9. Eur. J. Cancer 2011, 47, 600-610. [CrossRef]

33. Wang, C.; Mao, C.; Lai, Y.; Cai, Z.; Chen, W. MMP1 3'UTR facilitates the proliferation and migration of human oral squamous cell carcinoma by sponging miR-188-5p to up-regulate SOX4 and CDK4. Mol. Cell. Biochem. 2021, 476, 785-796. [CrossRef] [PubMed]

34. Ying, T.H.; Yang, S.F.; Tsai, S.J.; Hsieh, S.C.; Huang, Y.C.; Bau, D.T.; Hsieh, Y.H. Fisetin induces apoptosis in human cervical cancer HeLa cells through ERK1/2-mediated activation of caspase-8-/caspase-3-dependent pathway. Arch. Toxicol. 2012, 86, 263-273. [CrossRef]

35. Chen, C.M.; Hsieh, Y.H.; Hwang, J.M.; Jan, H.J.; Hsieh, S.C.; Lin, S.H.; Lai, C.Y. Fisetin suppresses ADAM9 expression and inhibits invasion of glioma cancer cells through increased phosphorylation of ERK1/2. Tumor Biol. 2015, 36, 3407-3415. [CrossRef] [PubMed]

36. Chao, R.; Chow, J.M.; Hsieh, Y.H.; Chen, C.K.; Lee, W.J.; Hsieh, F.K.; Yu, N.Y.; Chou, M.C.; Cheng, C.W.; Yang, S.F.; et al. Tricetin suppresses the migration/invasion of human glioblastoma multiforme cells by inhibiting matrix metalloproteinase-2 through modulation of the expression and transcriptional activity of specificity protein 1. Expert Opin. Ther. Targets 2015, 19, 1293-1306. [CrossRef]

37. Chang, C.W.; Hsieh, Y.H.; Yang, W.E.; Yang, S.F.; Chen, Y.; Hu, D.N. Epigallocatechingallate inhibits migration of human uveal melanoma cells via downregulation of matrix metalloproteinase-2 activity and ERK1/2 pathway. BioMed Res. Int. 2014, 2014, 141582. [CrossRef]

38. Liu, C.M.; Shen, H.T.; Lin, Y.A.; Yu, Y.L.; Chen, Y.S.; Liu, C.J.; Hsieh, Y.H. Antiproliferative and Antimetastatic Effects of Praeruptorin C on Human Non-Small Cell Lung Cancer Through Inactivating ERK/CTSD Signalling Pathways. Molecules 2020, 25, 1625. [CrossRef]

39. Huang, C.F.; Teng, Y.H.; Lu, F.J.; Hsu, W.H.; Lin, C.L.; Hung, C.C.; Tung, J.N.; Hsieh, Y.H.; Liu, C.J. beta-mangostin suppresses human hepatocellular carcinoma cell invasion through inhibition of MMP-2 and MMP-9 expression and activating the ERK and JNK pathways. Environ. Toxicol. 2017, 32, 2360-2370. [CrossRef]

40. Kim, J.H.; Kim, Y.H.; Song, G.Y.; Kim, D.E.; Jeong, Y.J.; Liu, K.H.; Chung, Y.H.; Oh, S. Ursolic acid and its natural derivative corosolic acid suppress the proliferation of APC-mutated colon cancer cells through promotion of beta-catenin degradation. Food Chem. Toxicol. 2014, 67, 87-95. [CrossRef]

41. Horlad, H.; Fujiwara, Y.; Takemura, K.; Ohnishi, K.; Ikeda, T.; Tsukamoto, H.; Mizuta, H.; Nishimura, Y.; Takeya, M.; Komohara, Y. Corosolic acid impairs tumor development and lung metastasis by inhibiting the immunosuppressive activity of myeloid-derived suppressor cells. Mol. Nutr. Food Res. 2013, 57, 1046-1054. [CrossRef]

42. Yoo, K.H.; Park, J.H.; Lee, D.Y.; Hwang-Bo, J.; Baek, N.I.; Chung, I.S. Corosolic Acid Exhibits Anti-angiogenic and Antilymphangiogenic Effects on In Vitro Endothelial Cells and on an In Vivo CT-26 Colon Carcinoma Animal Model. Phytother. Res. 2015, 29, 714-723. [CrossRef]

43. Zhang, B.Y.; Zhang, L.; Chen, Y.M.; Qiao, X.; Zhao, S.L.; Li, P.; Liu, J.F.; Wen, X.; Yang, J. Corosolic acid inhibits colorectal cancer cells growth as a novel HER2/HER3 heterodimerization inhibitor. Br. J. Pharmacol. 2021, 178, 1475-1491. [CrossRef] [PubMed]

44. Li, B.; Li, Y.; Wang, Q.; Li, F.; Li, F. Corosolic acid impairs human lung adenocarcinoma A549 cells proliferation by inhibiting cell migration. Oncol. Lett. 2019, 17, 5747-5753. [CrossRef]

45. Wang, K.; Zhu, X.; Yao, Y.; Yang, M.; Zhou, F.; Zhu, L. Corosolic acid induces cell cycle arrest and cell apoptosis in human retinoblastoma Y-79 cells via disruption of MELK-FoxM1 signaling. Oncol. Rep. 2018, 39, 2777-2786. [CrossRef] [PubMed] 
46. Woo, S.M.; Seo, S.U.; Min, K.J.; Im, S.S.; Nam, J.O.; Chang, J.S.; Kim, S.; Park, J.W.; Kwon, T.K. Corosolic Acid Induces NonApoptotic Cell Death through Generation of Lipid Reactive Oxygen Species Production in Human Renal Carcinoma Caki Cells. Int. J. Mol. Sci. 2018, 19, 1309. [CrossRef] [PubMed]

47. Fukushima, M.; Matsuyama, F.; Ueda, N.; Egawa, K.; Takemoto, J.; Kajimoto, Y.; Yonaha, N.; Miura, T.; Kaneko, T.; Nishi, Y.; et al. Effect of corosolic acid on postchallenge plasma glucose levels. Diabetes Res. Clin. Pract. 2006, 73, 174-177. [CrossRef]

48. Choi, M.S.; Ryu, R.; Seo, Y.R.; Jeong, T.S.; Shin, D.H.; Park, Y.B.; Kim, S.R.; Jung, U.J. The beneficial effect of soybean (Glycine $\max ($ L.) Merr.) leaf extracts in adults with prediabetes: A randomized placebo controlled trial. Food Funct. 2014, 5, 1621-1630. [CrossRef]

49. Stohs, S.J.; Miller, H.; Kaats, G.R. A review of the efficacy and safety of banaba (Lagerstroemia speciosa L.) and corosolic acid. Phytother. Res. 2012, 26, 317-324. [CrossRef] [PubMed]

50. Hsieh, Y.H.; Hsu, W.H.; Yang, S.F.; Liu, C.J.; Lu, K.H.; Wang, P.H.; Lin, R.C. Potential Antimetastatic Effect of Timosaponin AIII against Human Osteosarcoma Cells through Regulating the Integrin/FAK/Cofilin Axis. Pharmaceuticals (Basel) 2021, 14, 260. [CrossRef]

51. Wu, M.H.; Wu, P.R.; Hsieh, Y.H.; Lin, C.L.; Liu, C.J.; Ying, T.H. Silencing PROK2 Inhibits Invasion of Human Cervical Cancer Cells by Targeting MMP15 Expression. Int. J. Mol. Sci. 2020, 21, 6391. [CrossRef]

52. Chiang, K.C.; Lai, C.Y.; Chiou, H.L.; Lin, C.L.; Chen, Y.S.; Kao, S.H.; Hsieh, Y.H. Timosaponin AIII inhibits metastasis of renal carcinoma cells through suppressing cathepsin C expression by AKT/miR-129-5p axis. J. Cell. Physiol. 2019, 234, 13332-13341. [CrossRef] 